Wim Van Daele

Department of Social Anthropology, University of Oslo

PoBox 1091, Blindern, 0317 Oslo, Norway

Tel +4796741343, email: wimvandaele.x@gmail.com, w.v.daele@ sai.uio.no

This work was supported by the European Research Council under the European Union's Seventh Framework Programme (FP7/2007-2013) / ERC Grant Agreement nr 295843. 


\title{
Food as the Holographic Condensation of Life in Sri Lankan Rituals
}

\begin{abstract}
This paper seeks to elaborate the dynamics through which food acquires potency in shaping human life and organization as it takes shape in enacting ritual transformation. I argue that whereas life and various existential concerns get condensed from the fringes of the social order into ritual, food further holographically condenses the existential concerns of life with which it is entangled as an assemblage. As such, it turns into a centripetal force in ritual by constituting a means that enables ritual and somatic transformation to materialise in the matter of food and thus in helping to render ritual effective. To grasp this complex process we will look at the basic dynamic of holographic condensation throughout the different ways in which various foods ritually enact the regeneration of life in the astrological New Year and the Sătuwe anti-sorcery healing rite in a Sinhalese Buddhist village in the North-Western province of Sri Lanka.
\end{abstract}

\section{Key Words}

Food, Holography, Condensation, Sri Lanka, Ritual 
Food is central to human life and organisation because it is entangled with a vast range of heterogeneous components that it both condenses and shapes as an assemblage (Van Daele 2013a, 2016). In this paper I focus on the nature and dynamics of this condensation (Turner 1967, Leach 1976) as well as the power this process infuses in food to shape life. I will do so by specifically exploring the centripetal roles food preparations and offerings perform in enacting ritual transformation while engaging with the existential processes of precariousness and regeneration of life in contexts as different as the New Year transition and antisorcery healing. As the ritual unfolds, the food transforms simultaneously as it enacts its evolving role(s) throughout the event by getting connected with, and disconnected from, different components, whereby altering the composition of the elements that are holographically (Bohm 1980, Mosko 2005, 2010, Strathern 1995, 2004) condensed in the food as it becomes part of the whole it encompasses. This enables the joint unfolding of food and ritual action that enact each other in their entanglement and mutual becoming whereby food becomes a powerful agent to the extent that the efficacy of the entire rite often depends on the successful transformation and/or offering of food. Henceforth, this paper seeks to qualify the nature of the processes that enable food to perform a collaborative role (Janeja 2010) in dealing with human and more-than-human relationships that impinge on fundamental existential processes.

After first laying out my general approach to ritual, food and holography, I illustrate these transformative and holographic dynamics as they recur in the Sinhalese and Tamil New Year and particularly by focusing on the agential roles rice and coconut acquire in the overflowing of (coconut) milk rite or kiriutereme and the cooking of (coconut) milk-rice or kiribath. These two food items and their ritual preparations actually recur across many different rites in Sri Lanka, such as Poya or full moon days, birthdays, harvest events and life-cycle rites, whereby their cross-contextual performance turns them into reagents with a similar cross-contextual message or import and a different purport or specific role according to the particular context (Good 1983:224-225). The similar import revolves around the concern of a transition or regeneration toward a more prosperous, fertile, and healthy stage in life; transitions that are precarious and tie into the overall fragility of life. More broadly, in their differential repetition throughout numerous ritual contexts both food performances enact the regeneration and ontogenesis of human and more-than-human life, the world, and its interrelations (Van Daele 2013a, 2013b). These concerns and processes get condensed in context-specific variations of the enactment of the kiriutereme and kiribath whereby they perform different work and thus their purport shifts; a purport that thus turns specific in the New Year discussed here. 
Following the elicitation of these ritual processes with respect to the kiriutereme and kiribath, the attention shifts towards the transformative action that other food performs in collaboration with other non-human agencies in the event of the Sätuwe anti-sorcery healing rite. Here, particular food items-predominantly limes and ash pumpkin-get enacted by specific heterogeneous networks of myths, physical properties, and aspirations that they holographically condense, enabling them to turn into healing agents in this particular context.

\section{Ritual Transformation and Ontogenesis}

Don Handelman $(1998,2004)$ proposes a distinction between perspectives that approach ritual in terms of its role, function, and location in wider society, and perspectives that look at what ritual is about in its own respect. The former, he labels as the mirror model, given that it approaches ritual in terms of the wider roles or dynamics that it reflects (note the optic metaphor), re-presents, symbolizes, or expresses. The latter, he labels as the model model in terms of the ways in which rituals shape and model transformations. In the former, rituals derive their meaning from outside ritual, mirroring another order, whereas in the latter they generate transformative experience in a fairly autonomic way (Handelman 1998:xii-xv).

The numerous functionalist approaches, spearheaded by Bronislaw Malinowski (1984), E.E. Evans-Pritchard (1969), and Radcliffe-Brown (2006), are examples of the mirror model. They look at rituals not in their own right, but for their role in wider society, whether they are part of maintaining social orders by the reproduction of social and gendered identities, the selfnarration in symbolic ways, or as a function of resistance or outlet (Handelman 2004:2,16). By contrast, the model model studies ritual in its own right, at least for a moment, as to learn what ritual does in itself and for itself, only to return later to its connections with wider sociocultural orders (Handelman 2004:2). For instance, Victor Turner (1974) focuses on the ritual dynamic itself by drawing upon the seminal work of Arnold Van Gennep to discuss the liminal or threshold phase that accounts for the transformative potential of rites. In this phase between the entry and the exit of the ritual, symbols are recombined and reforged, and these symbolic explorations, subversions, and conversions allow the ritual participant to pass through a chaotic stage of intense engagements with new meanings. It is only after a separation that the rite and the participant torque back into the sociocultural order. The liminal stage and space is one of sheer potentiality, creative productions, and transformations, whereas the other phases entail actualizations and stabilizations. In the end, it is necessary to include both model and mirror models for an integrated understanding of ritual 
transformations and stabilizations in life, and the model approach is a prerequisite before turning back to the wider connections.

Other scholars located within the model approach include Edward Schieffelin (1985), René Devisch (1993) and Bruce Kapferer (1991, 1997, 2010, 2013) who have focused on the praxiological and actual transformational potential of ritual action. René Devisch (1993:37) foregrounds more specifically the body as "a genuine source of transformational symbolic creativity, of true praxis or action capable of intervening effectively on the world." Hence, ritual acts upon a mode of being-in-the-world and transforms this very being by way of somatic processes. Colourful images, particular smells, and sounds play a crucial role in this somatization where the body and the senses are mobilized as the site and instrument of the ritual creation of human realities in general and negotiation of existential concerns (Schieffelin 1985, Kapferer 1997:176-177, 2013:21). Such core existential concerns relate to the fragility of life, destructive desire, regeneration, and prosperity. Hence, ritual is effective not only because of the new symbolic connections that are forged, and its twisting back into society, but also, and maybe even more so, because of the performativity of the ritual events and the embodied experience of concerns it somatically engages and works with. I side with both René Devisch (1993) and Bruce Kapferer (2013) who approach ritual as a transformational or ontogenetic and (self-) generative process, and therefore offer a correction to the more textual, structural, and symbolic approach of Turner. Moreover, these authors regard ritual as being effective since it allows the condensation of life and the mobilization of psychic and bodily energies in bringing about desired transformations. This condensation and folding upon itself is a dynamic of ritual that Don Handelman (2004) seeks to foreground in his study of ritual.

I thus agree with Don Handelman $(1998,2004)$ along the lines set out by René Devisch and Bruce Kapferer that ritual has to be studied in itself and for itself, at least in a first stage, since we should not lose sight of its wider connections and implications, thus combining both model and mirror approaches. Additionally, we have to include a focus on the material entities that play a central role in the somatization and material elaboration of ritual action. In this focus, food deserves more attention given that its vibrant and lively materiality facilitates the somatic work through the body and the senses that enable the envisaged ritual transformation to materialize (in the double sense of actually occurring and also condensing into a material form). Its power to do so not only derives from an aesthetic stimulation of the senses to instil values (Sutton 2010:209), but even more from its sustained central role 
throughout other domains of life from which it blends more diverse elements that it ritually condenses. This cross-contextual centrality in life is what makes food different from other materials used in ritual condensation and renders it more powerful and resistant to change (Lemonnier 2012:156), explaining the striking continuities in its ritual forms and roles over time in Sri Lanka.

What is the nature of the role that food plays in this collaborative transformative ritual action? I argue that while ritual seeks to "condense life from the edges of the social order" (Devisch 1993:38), there is a secondary condensation of the ritual (and thus life) into food, reminiscent of the ritual condensation that Victor Turner (1967) and Edmund Leach (1976) discussed. Yet, the nature of this secondary condensation is more materially grounded than accounted for by these two authors, which is eloquently elaborated by Pierre Lemonnier (2012). In explaining condensation, Edmund Leach (1976:37) states that the abstract ideas and sense-images that are generated in the mind are projected onto the external world whereby these acquire manifest form. The dynamic of projection in which ideas are materialized into objects is a core element of ritual action, as it allows people to perform "technical operations which are beyond the capacity of the mind acting by itself" (Leach 1976:37). In his view, this materialization is of a symbolic order that is shaped by human meaning-making. Similarly, Victor Turner (1967:28) states that "many things and actions are represented in a single formation," which he affirms occurs in ritual symbols, and this blending of diverse domains of life in one artifact is what renders it so powerful in ritual action (Lemonnier 2012). According to Edmund Leach (1976), this symbolic materialization as condensation actually results from a combination of metonymic and metaphoric processes; that is of associations within a similar context and between different contexts respectively. An example of the combination of different contexts entails the overflowing of milk or kiriutereme that will be discussed more thoroughly later. In the physical context the coconut milk overflows, which in a biological context is seen as abundance, and which in a metaphysical context entails the heated renewal and ontogenesis of the whole world enabling future prosperity and abundance. These three associations are all condensed in the overflowing of milk in the ritual context to obtain a single experience of the sum of the different dimensions that are superposed (as in an orchestra where there is an integrated but not necessarily harmonious experience of a cocomposed sound). However, is it sufficient to render the ritual role of material objects or food as belonging to the realm of human meaning-making where concerns are projected on them, enabling human beings to perform technical acts of transformation? Bluntly stated, this would 
imply that the world was an extensive psychological Rorschach test where all human beings projected their psychological and culturally informed concerns onto all entities of the world. Leaving the somatic and material aspects out of analysis, it would not matter which materials were used for the ritual condensation, thus food becoming just one thing amongst others, since things acquire meaning only in the very act of human signification. In this way, the human/non-human divide is strengthened by a privileging of the human side in the analysis and focus. Yet, objects and related material practices in this world do exhibit various properties that spur particular processes of signification while limiting these processes simultaneously as well. In this regard, Alfred Gell (1975:154) previously discussed "biological analogy", where some biological features motivate specific interpretations above others. For instance, the physical possibility of the overflowing of cooking coconut-milk brought in contact with fire makes it resonate with abundance in other contexts. The white colour evokes life-giving substances and purifying power that render it suitable for food offerings to higher deities. Pierre Lemonnier (2012:138-139) further elaborates the material role of objects as assemblages by pointing out that they necessitate thinking together the material practices, cultural technology, social relations, representations, feelings, thoughts, and myths, and by exploring how artefacts and their making non-verbally communicate basic values and concerns to the minds of local actors. The convergence of thoughts and other aspects around these artefacts is what Pierre Lemonnier (2012:142) defines as the condensation of various kinds of social relations, representations, basic values, material practices, ancestral powers, etc.

I suggest that Edmund Leach also hints at this material anchorage or 'analogy' by pointing out that the objects in the ritual context always entail a mix of symbolic/metaphoric and metonymic operations, yet by conceptualizing these operations in this way he places this mix within the realm of human meaning-making. In fact, Victor Turner (1967:28) already highlights that in the dominant condensing symbol: "the disparate significata are interconnected by virtue of their common possession of analogous qualities or by association in fact or thought" (original emphasis omitted and mine added). This statement shows that Victor Turner also exhibited sensitivity to what we today call the 'material' aspects, but his rendering in terms of significata seems to imply an overemphasis on reference and the role of meaning rooted into the unconscious (Turner 1967:29).

The recent emphasis on the vital materiality of things (e.g. Bennett 2010, Barad 2007) and various non-human entities envisages escaping the human-centred conceptual apparatus and 
enhancing sensitivity to the fact that things' materialities neither determine their selection for a purpose nor are selected haphazardly by way of a Rorschach projection of the unconscious. Paying attention to the vibrant and lively materiality of objects and foods allows us to better discern their particular role and place in the ritual event, which is a collaborative co-event of both human and non-human elements. More specifically, food takes a core role in ritual transformation owing to its material properties. Indeed, a perishable item such as food is ideal to work with in ritually dealing with processes of life, illness, healing, death and regeneration as complex fundamental existential concerns. Food is subject to blossoming, ripening, withering, and rotting, and condenses these extensive and existential processes in itself, thereby aptly rendering them present and manageable to somatically work with in ritual transformation (see also Boylston 2013). Advocating a somatic approach to ritual is consistent with viewing food as an enabling condition for the transformative potential of ritual to materialize (in its double sense). Part of the power it obtains in this ritual condensation derives from the fact that food is equally powerful in dealing with these basic processes and related concerns in other contexts as well, and this goes to the heart of condensation where elements from different domains of life converge (Lemonnier 2012:143). The salience of food in these other realms thus further strengthens it as a potent condensation that is ritually good to work with in regenerating life.

In short, by paying attention to the very materiality of food in its enactment and relational ordering within a network of myths, material practices, and representations we can better understand the crucial role it plays in ritual action. Food condenses the ritual that itself condenses the various existential concerns that are dealt with by way of somatic and sensorial processes. An aspect that needs further clarification is the nature of the condensation that food performs within the ritual while it connects with various practices, concerns, objects, and significations. I have already highlighted that in the linguistic rendering of Edmund Leach, these connections between objects and concerns are neither merely metaphoric nor metonymic, but always both. How could we better describe these connections paying equal attention to matter and meaning while avoiding getting stuck in conceptual tools that evoke an overemphasis on psychological projection and/or meaning? In other words, how can we conceptualize food's ritual condensation in a holistic and integrated way to comprehensively account for its central and potent role? 


\section{The Holographic Condensation}

We could further clarify and specify food's condensation of ritual in itself by conceptualizing it as a holographic condensation of the assemblage it becomes in the ritual context, entailing that it is part of the rite that it simultaneously encompasses. In other words, food is enacted by the heterogeneous network of the ritual event, which it is simultaneously taking part in shaping. The overflowing milk, milk-rice, and other food offerings, become more than just the physical food or human signification; they are rather enacted as an assemblage of heterogeneous aspects, including flavours, practices, myths, colours, dynamics of decay, invisible beings, desires, health aspirations, and so forth. The notion of assemblage as I developed in relation to food in greater detail elsewhere (Van Daele 2013a, 2016) stresses that it is a resulting synthesis or enactment of diverging human and non-human aspects. The emergent whole is not reducible to the sum of parts, but the parts act on each other rather create a new resulting expression, open to ongoing transformation (DeLanda 2006:4-5). As such the food is: "a continuously generated effect of the webs of relations" (Law 2009:141). Everything, whether coinciding with visible boundaries or not, can be approached as an assemblage, but food is particularly dense and powerful as an assemblage passing through digestive channels that forge mutual transformation of both living beings and food. Adopting an assemblage approach is not very different from turning to material semiotics or actornetwork theory, since they share the repertoire of exhibiting sensitivity towards relationality, heterogeneity, materiality, process, non-linearity, and emergence (Law 1999, 2009, Mol 2010). The heterogeneous network that performs food as an assemblage becomes an enabling condition for it to turn into a holographic condensation of life in rituals. These foods in the ritual context contain specific aspects by way of which each of the foods turn into an integrated experience, as in the ritual condensation that Edmund Leach (1976) described.

There are two main reasons for elaborating the notion of holographic condensation. First, it stresses the point that food is part of the whole while it simultaneously contains the whole. Second, it gives due place to the materiality of food in the somatic transformation or becoming that ritual seeks to bring about.

Roy Wagner (2001:xx) observes that the holographic perspective is central in South Asian thinking and stretches out from the Indian subcontinent through Indonesia and Melanesia. An example is the Ayurvedic health system where the holographic relation is expressed clearly in viewing the person as part of and at the same time identical to the universe, since both are co- 
composed of similar elements, explaining their radical interpenetration (Osella \& Osella 2002). The interest in the holographic worldview spread also to European-American thinking as it took hold through fractal mathematics and the technology of hologram projection. By adopting the holographic approach we thus combine an emic perspective for theorizing the centrality of food in Sri Lankan society with a cross-cultural and interdisciplinary orientation whereby its relevance reaches beyond Asia as well.

The notion of holography derives from the Greek words holo or whole and graphe, meaning to write and draw. The holographic procedure is depicted below:
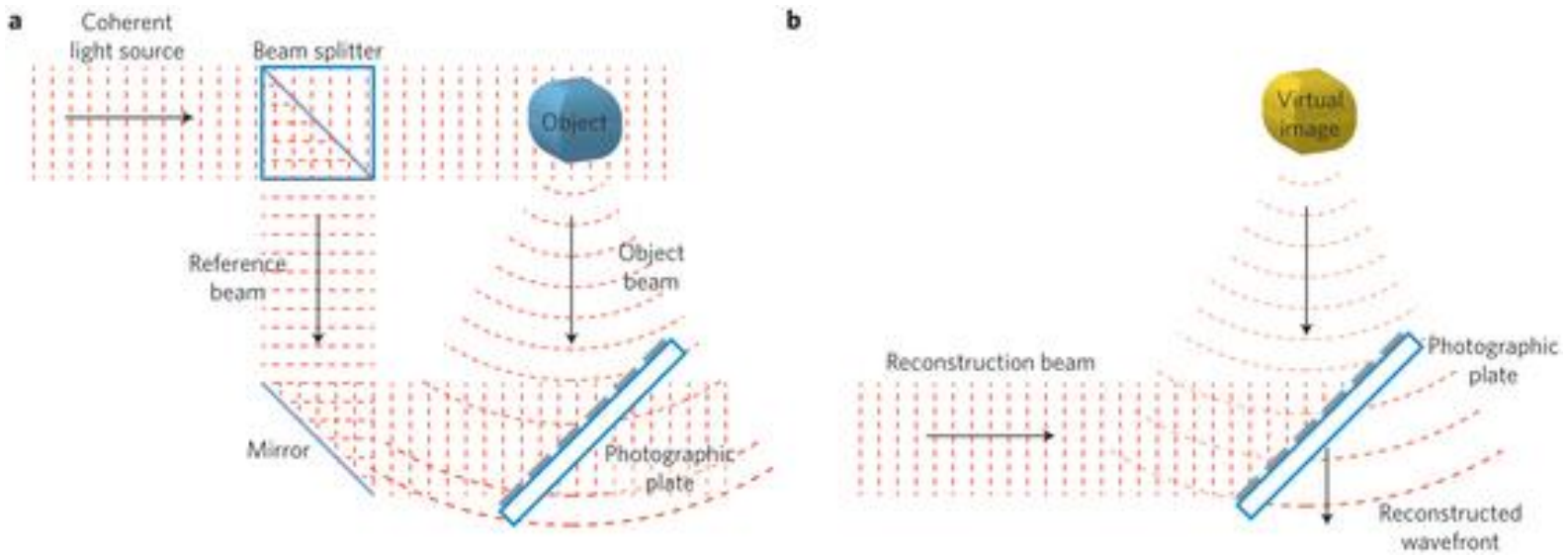

Figure 1, The holographic projection (reprinted by permission from Macmillan Publishers Ltd: Nature Nanotechnology 10(4):296-298, copyright 2015).

In the production of a hologram on a photographic plate, a laser beam shines through the lens spreading the beam onto an object of which some of the scattered light falls onto the lightsensitive photographic plate. The plate has a dense concentration of light-reactive grains that account for the high resolution that holograms require. The initial illumination beam shines onto the object where it is scattered as the object beam onto the recording surface. The beam splitter reflects the other part of the laser light onto a mirror such that it shines directly onto the photographic plate. This ray of light is called the reference beam. Both beams create a pattern of interference that is imprinted onto the plate during a specific time of exposure. On this plate, one sees apparently random black and white dots and all ranges of grey in-between. This is owing to the interference of the scattered light from the object and the original light source itself. The imprinted interference pattern encodes the scene onto the plate and constitutes the real hologram. Unlike many utilizations of the word hologram that incorrectly refer to the light projection, the material hologram is the imprint on the plate. When the object is taken away from the scene and an identical laser shines onto the hologram, the light is 
diffracted by the pattern on the plate and produces a light image identical to the object (Bohm 1980:183-184, Pitts 1990, Scheuer \& Yifat 2015, https://en.wikipedia.org/wiki/Holography, Diederik Aerts, personal communication, 25-10-2015).

The nature of the dots on the plate is important for our purposes. Each of these dots contains information about light scattered from the entire scene and thus contains information of the whole. As such, it becomes possible to break the photographic plate into two and still see the entire scene in each of the pieces, whereas in breaking a picture one would see only half. It is thus possible to break this plate again and again and see the entire image reproduced from each of the pieces, albeit with a lower resolution. By invoking the holographic dynamic of food, I stress that food as an assemblage contains information of the whole of which it is simultaneously part. In other words, it becomes "an example of the field it occupies" and this allows it to make connections everywhere (Strathern 1995:17). It is this holistic implication of holography that predominantly motivates its inclusion into the approach to food in ritual here. The multiplicity and heterogeneity that is holographically condensed into food shows that food, as an assemblage, becomes the enabling condition for occurrence of this type of condensation. Moreover, the heterogeneity and multiplicity implied in the holographic process sets it apart from the synecdoche wherein one aspect stands for the whole that it suffuses (Daniel 1984:107). As a consequence, the synecdoche is more reductionist, since only one element becomes dominant in the whole that it re-presents, whereas the holograph is more holistic as it contains the multiplicity of the whole within.

It is important to include in the introduction of the holographic some of its other implications that need to be considered and that complicate the situation of deploying the holographic approach in relation to everyday life situations. In the technical hologram projection, the whole scene is imprinted and encoded in each dot on the photographic plate, and as such the information on the small-scale of the dot is similar to the large-scale scene that is condensed in the dot. This motivates scholars adopting the holographic approach to focus on selfsimilarities across scales. Yet, this level of identical self-similarity is hard to find in everyday life since it is less reproducible than in such experimental settings where factors can be controlled. The recursivity in real life resonates rather with the similarities found in fractals. These are often seen as fancy images that exhibit self-similarities across scales, and which also occur in natural settings. Broccoli, for example, consists of smaller sections that look exactly similar to each other. Indeed, the recurring patterns and self-similarities in human and non-human relations are never identical, even though they can involve repetitions that entail 
differences as well (Deleuze 2013). In fact, the self-similarity of the holographic condensation itself should also not be overemphasized since it does not exactly entail identical relations in all aspects. If we break the photographic plate into a thousand pieces, the resolution of the hologram would decrease and the image would not be as sharp. Mark Mosko (2010:151) uses the notion of "fractal holography" to precisely nuance this holographic self-similarity, since the term fractal refers to a recurrence of a structure across different scales and where small differences may occur.

An important motivation for deploying the holographic notion entails its realist and material connection, since the holographic image evokes a true and factual projection of an object, contrary to the Rohrschach projection where people are invited to look at variable and diffuse ink patterns and to say what they see. The psychologist then discerns the preoccupations of the patient by way of the psychological projections the patients makes in seeing this or that particular form in the ink pattern. Hence, the Rohrschach model refers to the privileging of human interpretations. In our case, this would mean that any kind of signification could be pasted onto food and be unrelated to some of the heterogeneous aspects of it. This is a model which I question as one can see how meanings diverge but not completely disconnect from these heterogeneous properties. Recall that the condensation as discussed by Edmund Leach and Victor Turner stress the combination of both metonymic and metaphoric processes by way of which some leeway is given for variation, but in a way not entirely disconnected from the physical context. The conceptualisation of food as an assemblage that holographically condenses the rite simultaneously stresses the heterogeneity and self-similarity involved in this metonymic/metaphoric combination. The holographic relation is thus different from a purely metaphoric or Rorschach projection in that it remains connected to the shape and properties of the object and so not just any signification is pasted onto the object.

Stating that food is an assemblage that holographically condenses life and heterogeneous relations, initially seems to wed two incompatible notions, since the notion of assemblage stresses heterogeneity and holographic emphasizes self-similarity. Yet, the assemblage quality of food is precisely the enabling condition for it to holographically condense, since it is ritually enacted by a contextual network of heterogeneous components that it condenses within itself such that it becomes a modelling model within the ritual for a while, thereby affecting the rite and then torqueing back onto non-ritual contexts (Handelman 2004). Food turns into a powerful agent taking part through its entanglements in the shaping or modelling of life, rather than being a passive mirror reflecting another separate order. 
Throughout a wide variety of rituals, food is enacted by numerous components that it condenses whereby it becomes able to play a centripetal transformative and regenerative role. In Sri Lanka, this enactment converges often around rice and coconut as actualized in the form of the overflowing of coconut milk (kiriutereme) and the cooking of milk-rice (kiribath). As discussed in greater depth elsewhere (Van Daele 2013a, 2013b), these specific performances take place across rites as different as the New Year, wedding, harvest rituals, and many others that ponder precarious existential processes (their import) and seek to intervene in the situation to negotiate insecurities and to transform the situation for the better to get closer to the desired state. Hence, they condense these processes and seek to positively affect those. Yet, there are variations in their mode of preparation and thus the specific work (in terms of health, harvest, prosperity, and fertility) they perform within these varied contexts (their purport). Additionally, there are other foods and drinks that have a place in these rituals and perform different tasks in their specific articulation with other elements, such as in the cases of sharing meals and drinking alcohol that shape social relationships. The recurrent and different roles of rice and coconut, including in the form of kiriutereme and kiribath, as well as of other foods are now discussed in the specific cases of the New Year and the Sätuwe antisorcery healing rite.

\section{Sinhalese and Tamil New Year}

The New Year or Aluth Avurudda is an annual astrological event that takes place around the $13^{\text {th }}$ or $14^{\text {th }}$ of April. Nearly everybody returns home to their parental house in the village where they spend upwards to a week with family, friends, and fellow villagers. It is an energetic period filled with numerous lively encounters with food at the centre, during which specific foods perform particular roles as they are differentially enacted throughout the various happenings of the New Year period.

\section{New Year's Preparations}

The preparations for the holiday start days before the actual New Year. My host brothers and sisters arrive in the village a few days before and immediately start the preparatory work of cleaning the house and garden. Meanwhile, friends and relatives who have returned to the village pass by to greet us. We stop the work, offer biscuits and tea, and then continue on with our work. 
After the house and garden are cleaned, preparations for the habitual New Year sweets start. We begin by taking several bags of both steamed rice (tambapu hāl) and raw rice (käkulu hāl) to the mill to get it polished and a part of it pounded into rice flour. My youngest host brother, Kavith (the names are altered for reasons of privacy), and I go to collect fresh coconuts with the help of the coconut picker. His eldest sister, Vidusahani, sieves the dirt and lumps out of the rice flour, as my host brothers and I engage in a coconut scraping competition. Laughter and excitement fill the kitchen. The days before the New Year, the rhapsody of the vibrant food assemblage takes hold of the individual bodies and brings the entire household into an intensified collective rhythm and its variations.

The first of numerous New Year sweets we make is dodol - a rich, jelly-like candy made from coconut milk, rice flour, jaggery, and sugar. Some of us start by taking some of the grated coconut and add water to make milk that is set aside for later. We do this two more times to obtain three types of milk with different compositions. The younger host sister, Nihinsa, mixes the sieved rice flour, the second and third thinner extractions of coconut milk, jaggery, and plain sugar in a pan. We continuously fry and stir it for two hours scraping the hardening substance from the sides of the pan. As it hardens, we add the first milk extraction. The whole mixture becomes thick and difficult to stir, so we take turns over the next few hours. As the different aspects of the food assemblage transform in their entanglement with each other - rice, coconut, sugar, jaggery, heat, pan, stirring movements, duration-the continuously evolving enacted food takes us further into unfolding of the resulting food into a tasty New Year sweet, ready to get involved in the annual regeneration of relationships through its sharing.

\section{The New Year Transition and Liminal Idleness}

Whereas the days before the New Year are filled with the preparation of dodol and other special sweets that collaborate in the renewal of social and village relationships, the last day involves specific ritual preparations that help to ponder the life transition that the New Year entails. The numerous stages of the transition are determined by auspicious times as calculated by astrologers, and are announced nationally by the distribution of a New Year calendar and shown on television. The New Year then turns into a refined collective rhythmic event that tunes the individual lives of millions to resonate into a singular plural (Nancy 2000) body for a little while. These different stages are performed through technical acts (Leach 1976) to model, facilitate, and enact this transformation. The acts include two specific 
performances of rice and coconut that superpose different dimensions condensed into an integrated experience (as in the polyphonic concerto) whereby becoming potent agents of transformation.

Every year the fire at the hearth must be extinguished at a specific time according to the lunar calendar. This year, the time is exactly 6.23 p.m. (the specific timings in this narration are taken from 2009). From this point on the nonegathaya has started-the time when all activities come to a standstill. The hearth fire must be extinguished, all preparations should stop, and food and drink must not be consumed. Ideally, social interactions are reduced to a minimum, which allows time for idleness and contemplating ones deeds committed during the last year. Yet, if urgent preparations for the next stage are not finished, then people make a fire outside the house and continue to cook there. The idle period lasts until the next näkkat or auspicious time the following day. This nonegathaya bears the marks of a liminal stage (Turner 1974) of a ritual, marked by an anti-structure of nothingness and potentiality from which things will actualize during the further unfolding of the New Year as enacted and condensed in food and related practices.

\section{The Renewal of Domestic Life}

After this period of idleness and retreat, there follows a range of auspicious times to take into account. To make sure nothing is missed, Nihinsa turns on the television at 4:30 a.m. We dress in the determined auspicious cream colour, and prepare everything for the first ritual performance: the ritual overflowing of milk, which is a recurring and paradigmatic enactment of renewal of life. Much of the preparations-peeling and grating coconuts, making coconut milk, and cleaning the hearth — were finished before the nonegathaya period had started, so we can immediately start by pouring the milk in new earthen pots. We place the log on the hearth and while waiting watch the Rūpavāhinī national television channel to assure we are in tune with the first auspicious time. All the components are ready to enter into the ritual 'cooking pot' of potentiality from which emerge renewed entities.

At the first stage at 5:05 a.m., I am given the honour of lighting the hearth-fire and thus performing the lipa gini dälvime, whereby re-igniting the life in the house and in our family. We hope that the flames catch the entire set of logs, so that we can quickly start to perform the ritual overflowing of the coconut milk and prepare the milk-rice by 5:55 a.m. 
Once the fire is sufficiently burning we place a new earthen pot on the hearth, filled with enough milk to overflow in the four cardinal directions, a way of reaching out to encompass the world. To achieve this overflowing it is required to coordinate the heterogeneous processes of ritual cooking and continuously adjust the logs and fire. This overflowing of milk rite or kiriutereme is also broadcasted live from two locations and everywhere it goes smoothly (It would be interesting to observe the consequences of a broadcasted failed overflowing...). The overflowing of milk materializes and condenses abundance as it does also among Hindus in South Asia (Beck 1969:571) and among Tamil fishermen in Northern Sri Lanka for whom the boiling milk resembles an abundant catch with fish struggling in the water to escape the net (Tanaka 1997:118). Hence, in the New Year context it is deployed to effectuate the wish for prosperity in the coming year. Thereby, it acquires a divinational quality, since if the overflowing fails, it does not hold a good promise for the coming year. There is a tangible and somatic tension that builds among the spectators as they watch with excitement the milk ascend until it overflows out of the pot. The relief and ease afterwards is palpable, and in contrast to the building tension in the realm of potentiality until the actualization in the 'eruption' of the heated milk.

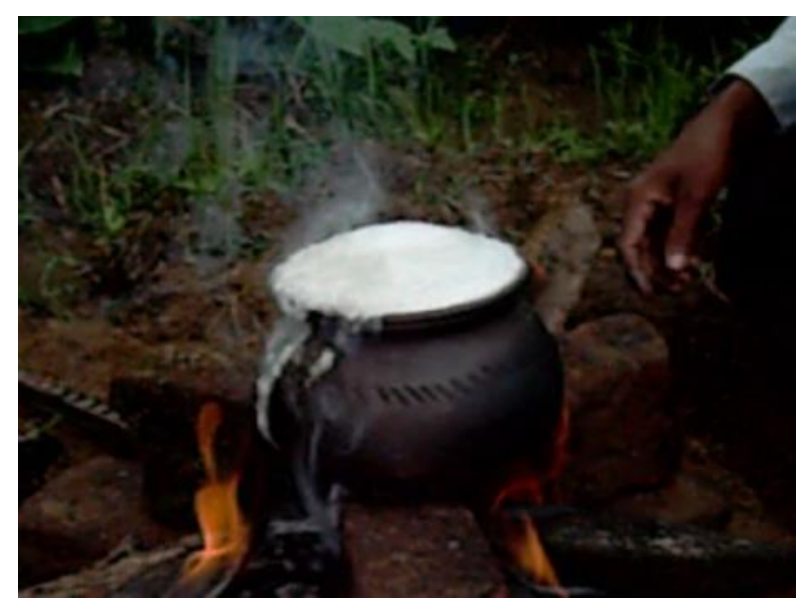

Picture 1: Kiriutereme (all pictures by author).

Immediately after the overflowing of the milk, Nihinsa adds the raw rice whereby drastically altering the food assemblage. The conjunction of rice and coconut-milk in the earthen pot evolves into the thick paste of milk-rice or kiribath that is eventually cut into pieces and finally presented on larger dishes to share with family members and neighbours during the following days when relationships are renewed through sharing kiribath and other New Year sweets. The adding of rice as a novel component affects the overall assemblage whereby the 
resulting food emerges as different, thus it is able to communicate and do different things as it enacts the further unfolding of the New Year event.

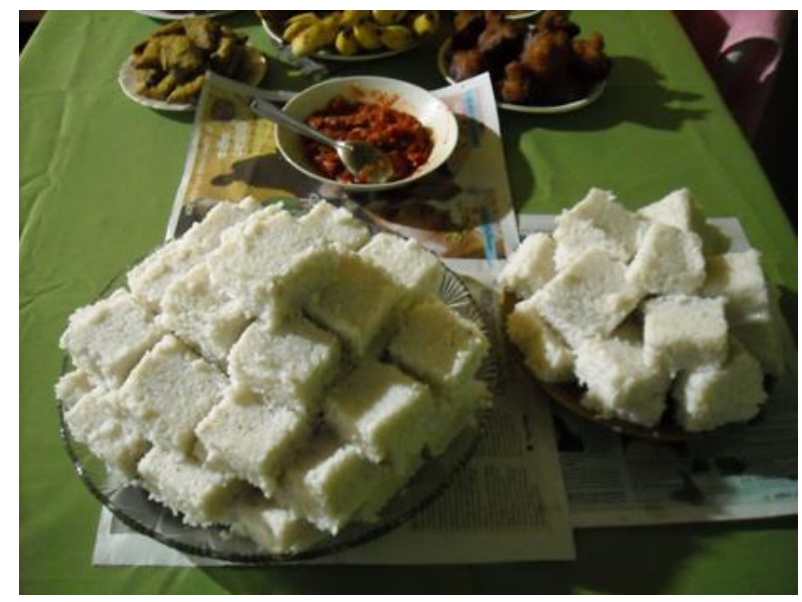

Picture 2: Kiribath.

The kiriutereme condenses a wide variety of elements that in their conjunction allow it to enact abundance and prosperity. Later, through the addition of novel elements, it evolves into kiribath, which is a pure food that plays an important role in the regeneration of human and more-than-human relationships. Along with the more physical and visible components-logs, fire, new earthen pot, coconut milk, duration, rice-invisible and meaningful aspects also get adsorbed into the two heterogeneous assemblages of kiriutereme and kiribath,

\section{The Holographic Condensation of Life in the Kiriutereme and Kiribath}

As part of the less tangible components that kiriutereme and kiribath articulate across the New Year and other contexts, there is one cosmological/mythological element enters into the ritual "cooking pot," and which corroborates their core role in regenerating and transforming life. In the Buddhist Agañna Sutta, the milky primordial sea evolved into the first earth essence having the qualities of milk-rice (Collins 1993:342). I suggest that the originary movement from fluid sea to solid earth becomes holographically condensed in the cooking of milk and milk-rice enacting a "primordial pulse of life" of the preterit origination of the world; a suggestion enhanced by villagers mentioning this particular text in this context. As such, these ritual items and cooking procedures condense and enact the present re-origination and regeneration of life as part of the world's becoming and renewal in the general "cooking" of the world (Malamoud 1996). 
Another element is that coconut-milk and milk-rice are deemed pure offerings suited for deities that occupy a higher position in the Sinhalese Buddhist cosmology. All beings, including deities, are subject to the cosmic law of samsara, the cycle of death and rebirth, and their position is affected by their karma, the balance of beneficial and destructive deeds (Kapferer 1997:32). By exchanging food for protection both human beings and deities perform good deeds and acquire merit and thus improve their position in the Buddhist pantheon (Obeyesekere 1963:142-147, 1987:50-70). By acquiring merit, their karmic position improves and both get closer to nirvana and/or closer to Buddhahood, thereby reconfiguring the cosmos. Accepting anything (e.g. meat or polluted food) other than pure food offerings like milk-rice (Kapferer 1997:145), would lower the higher deities within the pantheon and upset their Buddhist aspirations. Thus, food collaborates in the regeneration of the cosmos within which relative positions of both human and non-human beings are renegotiated (Van Daele 2013a:40). Since food is entangled with all these heterogeneous concerns and cosmological aspects, it holographically condenses them, thereby turning into a cosmogenic agent that shapes the cosmos in its relational sharing and gift economy.

The performance of the kiriutereme and the ritual cooking of kiribath as particular articulations of rice and coconut help ponder precarious existential processes and enact desired outcomes and transformations (import). Both foods and their enactments are relational effects in that they emerge within different contexts and a set of varied components-fire, logs, earthen pot, human aspirations, non-human forces, temporality of cooking, myths, and existential processes - that they holographically condense whereby they can do context-specific work (purport). In the context of New Year, rice and coconut perform predominantly a renewal of relationships (especially in the form of sweets and kiribath) and seek to divine and effectuate a prosperous new year (kiriutereme), whereas in the context of cultivation, they enable to ponder the fragility of life as dependent on more-than-human relationalities, and collaborate in the intervention in the cosmological world to obtain good harvests. In the wedding event they enact, in multiple forms, the desired fertility, prosperity, and good health for the wedding couple. All the different context-related processes, components, and messages get condensed in the enactments of these food preparations whereby these come to contain the whole information of the ritual event, thus holographically condense it. Thereby these foods become able to serve as potent agents effectuating transformations, something that is further foregrounded in the ritual discussed next. 


\section{Sätuwe}

The Sātuwe is a ritual that seeks to undo a preta bandana, a sorcery act that "ties" a house and its inhabitants to the influence of pretas. Such a curse often affects the members of the household in a detrimental way. They may get all sorts of illnesses, lose control over their desires, and experience a diminishing of the ability to act according to a free intentionality, in short having their agency impaired. The ritual essentially cuts the incarcerating ties with the pretas so that the afflicted can heal and restore their sense of being.

\section{Preparing for the Rite}

Everyone who wishes to participate in the rite is advised to take a bath for purification. The participants are asked to avoid any foods that are polluting (pili) - eggs, fish, or any kind of meat — which could attract the pretas. Especially for those afflicted by the preta bandana, this avoidance helps decrease the strength of their incarcerating influences. They must observe these dietary precautions for an additional 21 days and are moreover not allowed to eat jungle meat - deer and wild boar-for a whole year to prevent possible returns of these malicious ghosts. In this context, food becomes an assemblage of various properties that are mobilized and turn it into a core healing and preventive agent.

\section{Obtaining Varam}

In the first stage of the ritual, the kapurāla utters mantras (verses) to ask varam from the deities who are under supervision of the Buddha in what Gananath Obeyesekere (1963:142147, 1987:50-70) terms the "Sinhalese Buddhist pantheon." This varam entails a kind of permission and authority from which the priest derives power from the deities and ultimately from the Buddha to deal with the lesser beings and perform the rite. To bring about a voluntary mood in the deities, they are offered the finest, best-looking, sweet smelling, and seductive food offerings to increase the success of the rite. They are placed on the table in front of the kapurāla in a network of heterogeneous elements through which the food gets enacted as a tool for cosmic intervention and ritual healing. The offering assemblage includes an ash pumpkin, five types of sweets, rice and boiled (not fried) vegetables, fresh pieces of fruit, as well as the offerings of betel leaves, areca nuts, limes, five types of oil, burning incense, sand, and king coconuts (Thembili, a native variety of the Cocos Nucifera). 


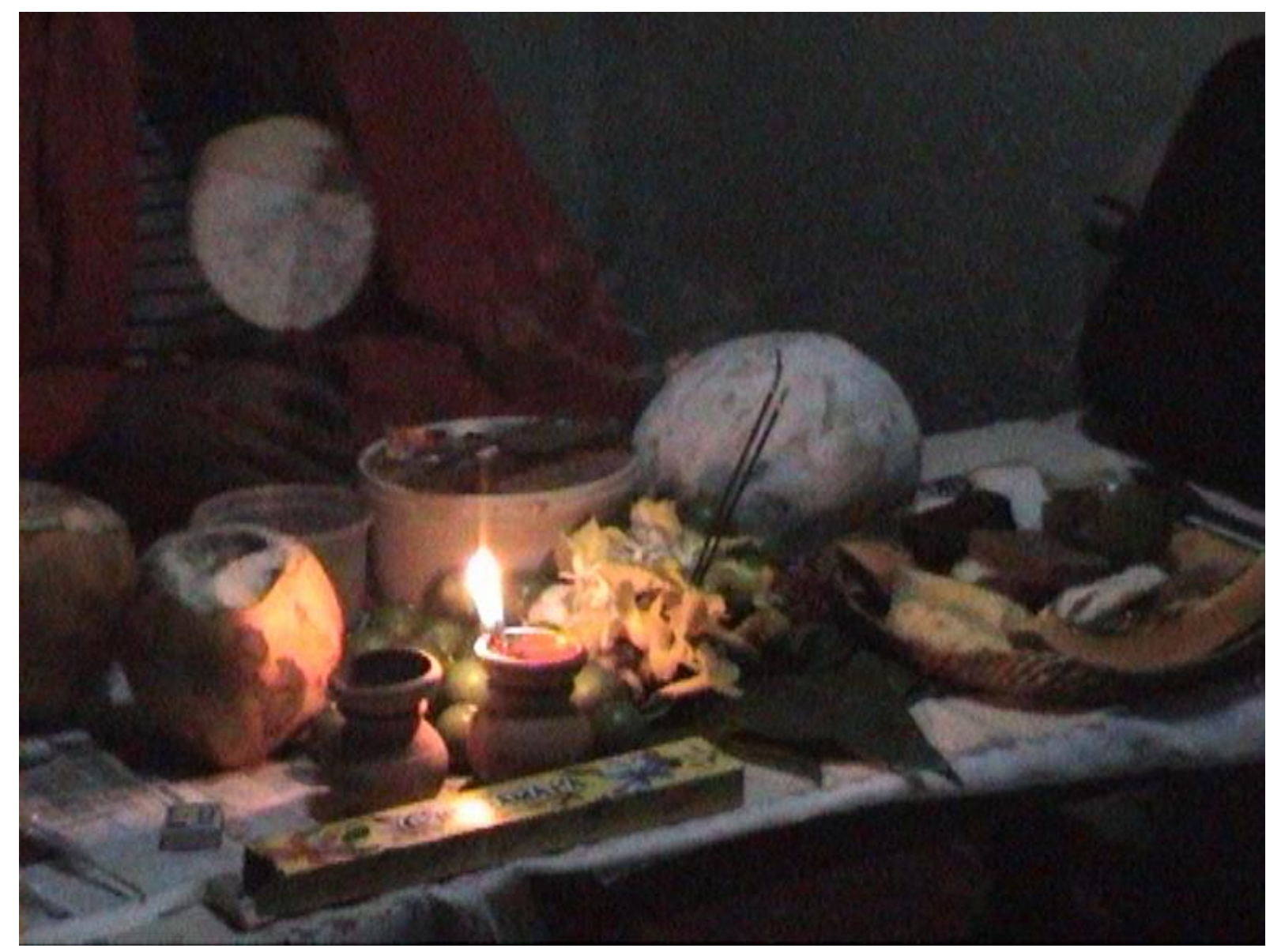

Picture 3: Food offerings to obtain varam.

These offerings are kept strictly separate from the overripe food offerings and fried meats for the pretas at all times to avoid any possible mixing up. If offerings unsuitable for deities ended up on their table, it could cause potential upheaval, as the cosmic hierarchy would be disrespected; a hierarchy shaped through food (owing to their Buddhist aspiration and abstinence from meat). Indeed, in this context food again actualizes as a generator and guardian of cosmological distinctions that are fragile and prone to unwarranted transformations. The perishable nature of food has to be carefully dealt with to render the offering potentially effective. Indeed, throughout this rite, food is one of the main agents in restoring the well-being and health of the afflicted family, and is thus cautiously handled.

\section{Dehi Käpīme}

When the varam and blessing have presumably been obtained, the dehi käpime rite is performed. The kapurāla takes a fried lime (that has just been fried outside) and while chanting verses against ill-health and for protection, he moves the lime back and forth over the limbs of one of the afflicted people. Coming towards the feet or hands, he cuts the lime 
with the areca nut cutter. The lime, which in itself is mythologically connected with poison, has a poison-destroying power as well (Kapferer 1997:148), and it absorbs the "poison" of the preta dosa (affliction caused by pretas) and the incarcerating bond with the preta is undone when the kapurāla cuts the lime. He immediately puts the cut lime in a box, as in absorbing the poison it has turned into a dangerous agent. If somebody steps on it, the dosa could be transferred onto him or her (Bastin 2002:68). The kapurāla repeats this act several times and then he fries the limes in the mixture of five beneficial oils to transform them and their sap into a healing, cleansing, and protective agent where the poison is destroyed (Kapferer 1997:171). The kapurāla then rubs the limbs of the afflicted with this oil for healing purposes.

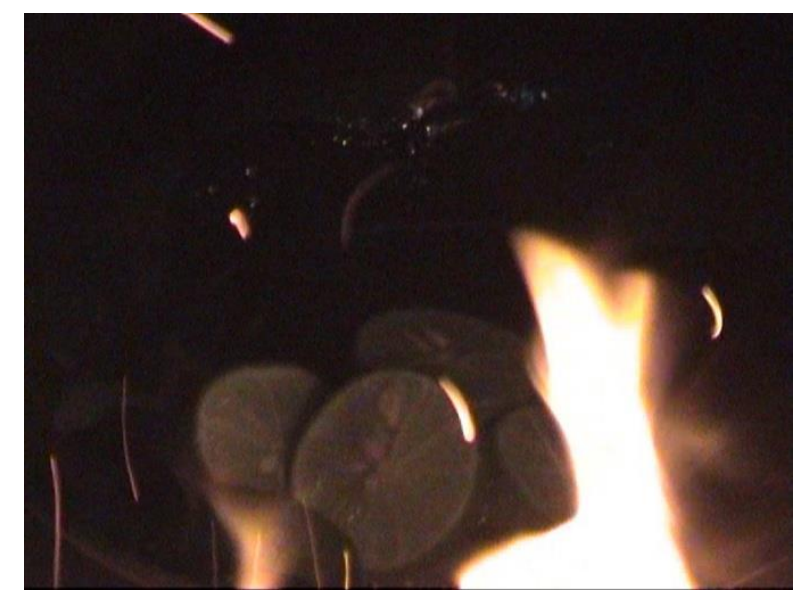

Picture 4: Frying lime to turn it into a healing agent.

The lime has thus actualized as a healing agent through the establishment of connections with heterogeneous material and mythological elements and practices with which it has become entangled and which it holographically condenses, enabling it to become a powerful collaborator in the healing process of the antisorcery event. The cutting of the lime enacted and effectuated the undoing of the bond with the pretas. However, their influence is still palpable in the house and stopping the rite at this point would mean that the living kinsmen could easily be affected again. Therefore, the house also has to be purified and cut away from the sorcery's incarceration.

\section{Puhul Käpīme}

The cutting of the ash pumpkin or the puhul käpime when the kapurāla exits the house enacts the cutting of the tie from the house and its inhabitants to the sorcery and the pretas. The victims of the house then become regenerated and reborn as liberated beings having regained control over their own desires and intentionalities. The käpime that takes place in my area of 
research is less elaborate than in a similar rite that Bruce Kapferer (1997:174-175) describes, yet the sacrificial component seems to be present in both. Through cutting the ash pumpkin serving as a surrogate sacrifice the victim becomes an active agent of transformation by sacrificing the bond with preta. The pumpkin gets connected with these components, relationships, and existential concerns with precariousness of life, desire, and well-being that converge in this pumpkin as an assemblage that holographically condenses these components, enabling it to operate as a substitute of self-sacrifice and thus to actualize as a healing agent in the unfolding of the rite. It condenses and enacts the transformation of the victim into a being with the ability to give their own life the aspired direction. The sacrifice of the pumpkin consists of a process of cutting that involves "destruction that ends on a note of creation or reorigination," by way of which the victim breaks free from the inhibiting bond of sorcery (Kapferer 2013:33).

\section{Securing the Compound}

After securing the house, the attention turns to freeing the compound from the preta dōsa. The basket with food offerings for the pretas has to be carried outside of the compound, opposite to the entry gate. By way of the pretas' immense greed and craving, which can never be satisfied due to their tiny throats, they get anchored to the food outside until the moment they catch something more attractive. As such, Bruce Kapferer (1997:123) notes: "the removal of the basket re-establishes the boundaries of the house and household and externalizes the malevolence of social relations (their death-dealing possibility), opening the way for their more positive redefinition." The family inhabiting the compound purifies itself by expelling destructive forces of the sorcery to the external territory, thereby re-establishing also the boundary between the internal and external forces of the personhood. Indeed, a preta bandana destabilizes one's being at its intimate core. 


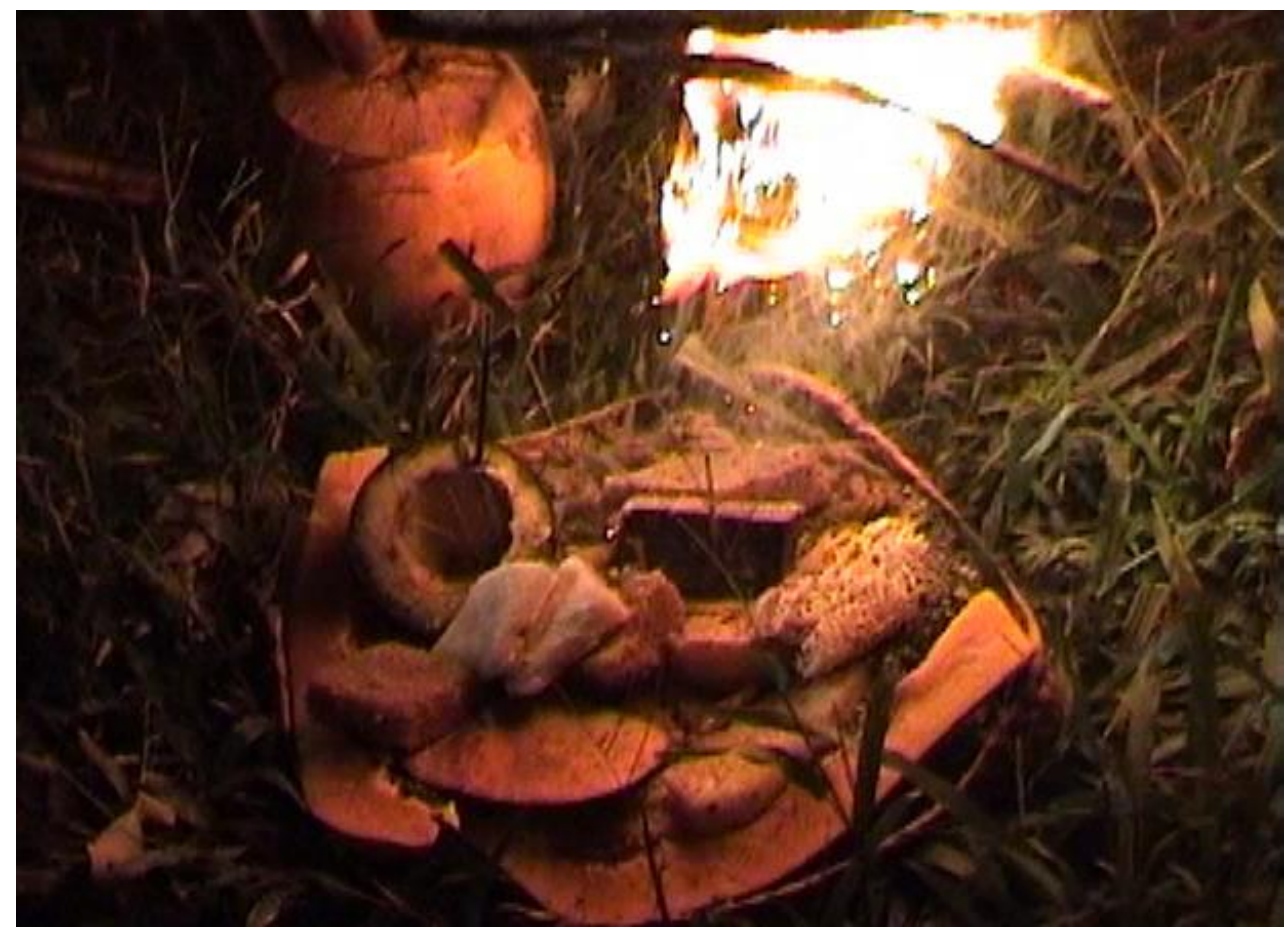

Picture 5, Food offerings for the pretas outside the compound.

To sum up, with the help of food, the afflicted inhabitants of the compound turned from objects of sorcery into subjects taking life into their own hands, hence becoming agents again, able to deal with chaotic forces and energies of life.

\section{Conclusion}

Food plays a centripetal role in the regeneration of life throughout different rituals. In Sri Lanka, rice and coconut, in their differential articulation and enactment by heterogeneous components and contexts, perform the renewal of human and non-human relationships, divine and effectuate a prosperous time to come, help to ponder the fragility of life, and seek to enhance the fertility of cultivation and the marrying couple. During the New Year, both foods articulate into numerous sweets, such as dodol, which take part in regenerating social relationships as well as into the kiriutereme and kiribath that perform these and additional existential roles. In the Sätuwe context, other foods become central in performing different kinds of work vis a vis deities and hungry ghosts as well as enabling surrogate sacrifices, all collaborating toward healing people afflicted by sorcery. Focussing on food enables to understand how it becomes a core ritual tool with which people collaborate to intervene in their situation to deal with existential concerns and the regeneration of life as interrelational with other human and non-human entities and forces. Food can play this central role of collaborator since all the context-related processes, components, and messages get condensed 
in the enactments of these foods and their preparations, whereby these come to contain the whole information of the ritual event and thus holographically condense it. Moreover, as the ritual events unfold, food jointly enacts this process as it is entangled with it. By focussing on food in this process of collaboration with other human and non-human agents in shaping the ritual unfolding, the sensitivity increases to both material and significatory aspects that take part and even enable the ritual transformation to occur in somatic and sensorial ways. Indeed, the somatic transformative approach to ritual is consistent with the focus on food through which these processes of renewal and healing get enacted. As such, this focus allows to turn attention to the various ways in which rituals in Sri Lanka and elsewhere are co-events of practical, physical, technical, magical, sensorial, and somatic processes of transformation that emerge in the interrelational enmeshment of the human and non-human.

\section{Acknowledgements}

I would like to warmly thank Vito Laterza, Marianne Lien, and Thomas Hylland Eriksen for their comments on earlier drafts, however none of them bears any responsibility for the views expressed here.

\section{References}

Barad Karen. 2007. Meeting the Universe Halfway: Quantum Physics and the Entanglement of Matter and Meaning. Durham: Duke University Press.

Bastin, Rohan. 2002. The Domain of Constant Excess: Plural Worship at the Munnesvaram Temples in Sri Lanka. New York: Berghahn Books.

Beck, Brenda E.F. 1969. Colour and Heat in South Indian Ritual. Man 4(4):553-572.

Bennett, Jane. 2010. Vibrant Matter: A Political Ecology of Things. Durham: Duke University Press.

Bohm, David. 1980. Wholeness and the Implicate Order. London: Routledge Classics.

Boylston, Tom. 2013. Food, Life, and Material Religion in Ethiopian Orthodox Christianity.

In A Companion to the Anthropology of Religion, edited by, Boddy, Janice, \& Michael, Lambek. pp. 257-273. Malden, MA: Wiley Blackwell. 
Collins, Steven. 1993. The Discourse on What is Primary (Agañna-Sutta): An Annotated Translation. Journal of Indian Philosophy, 21(4):301-393.

Daniel, Valentine. 1984. Fluid Signs: Being a Person the Tamil Way. Berkeley: University of California Press.

DeLanda, Manuel. 2006. A New Philosophy of Society: Assemblage Theory and Social Complexity. London: Continuum.

Deleuze, Gilles. 2013[1968]. Difference and Repetition. Paul Patton, trans. London: Bloomsbury.

Devisch, René. 1993. Weaving the Threads of Life: The Khita Gyn-Eco-Logical Healing Cult Among the Yaka. Chicago: University of Chicago Press.

Evans-Pritchard, Edward E. 1969[1940]. The Nuer: A Description of the Modes of Livelihood and Political Institutions of a Nilotic People. New York: Oxford University Press.

Gell, Alfred. 1975. Metamorphosis of the Cassowaries: Umeda Society, Language and Ritual. London: The Athlone Press.

Good, Anthony. 1983. A Symbolic Type and its Transformations: The Case of South Indian Ponkal. Contributions to Indian Sociology, 17(2):223-244.

Handelman, Don. 1998. Models and Mirrors: Towards an Anthropology of Public Events. New York: Berghahn Books.

—. 2004. Why Ritual in Its Own Right? How So? Social Analysis, 48(2):1-32.

Janeja, Manpreet. 2010. Transactions in Taste: The Collaborative Lives of Everyday Bengali Food. New Delhi: Routledge.

Kapferer, Bruce. 1991. A Celebration of Demons: Exorcism and the Aesthetics of Healing in Sri Lanka. Washington: Smithsonian Institution Press.

-. 1997. The Feast of the Sorcerer: Practices of Consciousness and Power. Chicago: University of Chicago Press.

-. 2010. In the Event-Toward an Anthropology of Generic Moments. Social Analysis, 54(3):1-27. 
-. 2013. Montage and Time: Deleuze, Cinema, and a Buddhist Sorcery Rite. In Transcultural Montage, edited by Suhr, Christian, \& Rane, Willerslev. pp. 20-39. New York: Berghahn Books.

Law, John. 1999. After ANT: Complexity, Naming and Topology. The Sociological Review, 47(S1):1-14.

- 2009. Actor Network Theory and Material Semiotics. In The New Blackwell Companion to Social Theory, edited by Turner, Bryan. pp.141-158. Malden, MA: Blackwell Publishing.

Leach, Edmund. 1976. Culture and Communication: The Logic by Which Symbols Are Connected. Cambridge: Cambridge University Press.

Lemonnier, Pierre. 2012. Mundane Objects: Materiality and Non-Verbal Communication. Walnut Creek, CA: Left Coast Press.

Malamoud, Charles. 1996. Cooking the World: Ritual and Thought in Ancient India. Delhi: Oxford University Press.

Malinowski, Bronislaw. 1984[1922]. Argonauts of the Western Pacific: An Account of Native Enterprise and Adventure in the Archipelagos of Melanesian New Guinea. Long Grove, IL: Waveland Press.

Mol, Annemarie. 2010. Actor-Network Theory: Sensitive Terms and Enduring Tensions. Kölner Zeitschrift für Soziologie und Sozialpsychologie. 50(1):253-269.

Mosko, Mark S. 2005. Introduction: A (Re)Turn to Chaos: Chaos Theory, the Sciences, and Social Anthropological Theory. In On the Order of Chaos: Social Anthropology and the Science of Chaos, edited by Mosko, Mark S., \& and Frederick H., Damon. pp.1-46. New York: Berghahn Books.

—. 2010. Deep Wholes: Fractal Holography in Trobiand Agency and Culture. In Experiments in Holism: Theory and Practice in Contemporary Anthropology, edited by Otto, Ton, \& Nils, Bubandt. pp. 150-173. Malden: Wiley-Blackwell.

Nancy, Jean-Luc. 2000. Being Singular Plural. Robert D. Richardson and Anne E. O’Byrne, trans. Stanford: Stanford University Press. 
Obeyesekere, Gananath. 1963. The Great Tradition and the Little in the Perspective of Sinhalese Buddhism. The Journal of Asian Studies, 22(2):139-153.

—. 1987. The Cult of the Goddess Pattini. Delhi: Motilal Banarsidass.

Osella, Filippo, \& Caroline, Osella. 2002. Quelques points de vue sur l'inné et l'acquis au Kerala, Inde du Sud. In Images du corps dans le monde hindou, edited by Bouillier, Véronique, \& Gilles, Tarabout. pp. 467-495. Paris: CNRS editions.

Pitts, Mary E. 1990. The Holographic Paradigm: A New Model for the Study of Literature and Science. Modern Language Studies. 20(4):80-89.

Radcliffe-Brown, Alfred R. 2006. On Social Structure. In Anthropology in Theory: Issues in Epistemology, edited by Moore, Henrietta, \& Todd, Sanders. pp. 122-127. Malden: Blackwell Publishing.

Scheuer, Jacob, \& Yuval, Yifat. 2015. Holography: Metasurfaces Make It Practical. Nature Nanotechnology. 10(4):296-298.

Schieffelin, Edward L. 1985. Performance and the Cultural Construction of Reality. American Ethnologist, 12(4):702-724.

Strathern, Marilyn. 1995. The Relation: Issues in Complexity and Scale. Cambridge: Prickly Pear Press.

—. 2004. Partial Connections. Updated Edition. Walnut Creek, CA: Altamira Press.

Sutton, David E. 2010. Food and the Senses. Annual Review of Anthropology. 39:209-223.

Tanaka, Masakazu. 1997[1991]. Patrons, devotees and goddesses: ritual and power among the Tamil fishermen of Sri Lanka. New Delhi: Manohar.

Turner, Victor. 1967. The Forest of Symbols: Aspects of Ndembu Ritual. Ithaca: Cornell University Press.

—. 1974 Dramas, fields, and metaphors: Symbolic action in human society. Ithaca, New York: Cornell University Press.

Van Daele, Wim. 2013a. Igniting Food Assemblages in Sri Lanka: Ritual Cooking to Regenerate the World and Interrelations. Contributions to Indian Sociology, 47(1):33-60. 
-. 2013b. Fusing Worlds of Coconuts: The Regenerative Practice in Precarious LifeSustenance and Fragile Relationality in Sri Lanka. The South Asianist, 2(2):97-118.

- 2016. Vibrantly Entangled in Sri Lanka: Food as the Polyrhythmic and Polyphonic Assemblage of Life. Foundations of Science. doi:10.1007/s10699-016-9509-4, Electronic document, accessed 21.12.2016.

Wagner, Roy. 2001. An Anthropology of the Subject: Holographic Worldview in New Guinea and Its Meaning and Significance for the World of Anthropology. Berkeley: University of California Press.

Wikipedia, Holography, https://en.wikipedia.org/wiki/Holography, Electronic document, accessed 04.12.2015.

\section{List of Figures}

Picture 1: Kiriutereme (all pictures by author).

Picture 2: Kiribath.

Picture 3: Food offerings to obtain varam.

Picture 4: Frying lime to turn it into a healing agent.

Picture 5, Food offerings for the pretas outside the compound.

Figure 1, The holographic projection, reprinted by permission from Macmillan Publishers Ltd: Nature Nanotechnology 10(4):296-298, copyright 2015 